\title{
Tissue-specific dysregulation of 11ß-hydroxysteroid dehydrogenase type 1 in overweight/obese women with polycystic ovary syndrome compared with weight-matched controls
}

\author{
Alessandra Gambineri, Flaminia Fanelli, Federica Tomassoni, Alessandra Munarini, \\ Uberto Pagotto, Ruth Andrew' ${ }^{1}$, Brian R Walker' and Renato Pasquali \\ Division of Endocrinology, Department of Medical and Surgical Science, Centre for Applied Biomedical Research \\ (C.R.B.A.), S. Orsola-Malpighi Hospital, University of Bologna, University Alma Mater Studiorum, Via Massarenti 9, \\ 40138 Bologna, Italy and 'Endocrinology Unit, Queen's Medical Research Institute, University/British Heart \\ Foundation Centre for Cardiovascular Science, University of Edinburgh, Edinburgh, Scotland, UK
}

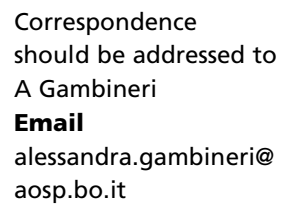

\begin{abstract}
Context: Abnormal cortisol metabolism in polycystic ovary syndrome (PCOS) has been invoked as a cause of secondary activation of the hypothalamic-pituitary-adrenal axis and hence androgen excess. However, this is based on urinary excretion of cortisol metabolites, which cannot detect tissue-specific changes in metabolism and may be confounded by obesity.

Objective: To assess cortisol clearance and whole-body and tissue-specific activities of $11 \beta$-hydroxysteroid dehydrogenase type 1 (11ß-HSD1 (HSD11B1)) in PCOS.

Design: Case-control study.

Setting: Medical center.

Patients: A total of 20 overweight-obese unmedicated Caucasian women with PCOS, aged 18-45 years, and 20 Caucasian controls matched for age, BMI, body fat distribution, and HSD11B1 genotypes (rs846910 and rs12086634).

Main outcome measures: Cortisol metabolites were measured in $24 \mathrm{~h}$ urine. During steady-state 9,11,12,12-[ $\left.{ }^{2} \mathrm{H}\right]_{4}$-cortisol infusion, cortisol clearance was calculated and whole-body HSD11B1 activity was assessed as the rate of appearance of $9,12,12-{ }^{2} \mathrm{H}_{3}$-cortisol (d3-cortisol). Hepatic HSD11B1 activity was quantified as the generation of plasma cortisol following an oral dose of cortisone. Subcutaneous adipose HSD11B1 activity and HSD11B1 mRNA were measured, ex vivo, in biopsies. Results: Urinary cortisol metabolite excretion, deuterated cortisol clearance, and the rate of appearance of d3-cortisol did not differ between patients with PCOS and controls. However, hepatic HSD11B1 conversion of oral cortisone to cortisol was impaired $(P<0.05)$, whereas subcutaneous abdominal adipose tissue HSD11B1 mRNA levels and activity were increased $(P<0.05)$ in women with PCOS when compared with controls.

Conclusions: Tissue-specific dysregulation of HSD11B1 is a feature of PCOS, over and above obesity, whereas increased clearance of cortisol may result from obesity rather than PCOS.

European Journal of

Endocrinology

(2014) 171, 47-57
\end{abstract}

(c) 2014 European Society of Endocrinology Printed in Great Britain 


\section{Introduction}

An important level of control of glucocorticoid action in humans is exerted by peripheral metabolism of cortisol by tissue-specific enzymes, in particular A-ring reductases ( $5 \alpha$ and $5 \beta$-reductase) in the liver and $11 \beta$-hydroxysteroid dehydrogenase type 2 (11ß-HSD2 (HSD11B2)) in the kidney (1). The metabolic clearance rate of cortisol is also influenced by the extent of regeneration of cortisol from inactive cortisone by $11 \beta$-HSD type 1 (11ß-HSD1 (HSD11B1)) in liver and adipose tissue $(1,2)$.

Adipose tissue, as well as liver, is a key target tissue in which glucocorticoid action influences susceptibility to obesity and metabolic complications. Transgenic mice overexpressing HSD11B1 selectively in adipose tissue develop obesity, particularly in visceral depots, insulin resistance, and all the features of the metabolic syndrome (3). A similar level of overexpression of $H s d 11 b 1$ selectively in liver does not induce obesity but impairs insulin sensitivity, promotes dyslipidemia, and increases blood pressure (4). Conversely, $H s d 11 b 1$ knockout mice fed on a high-fat diet are protected from obesity and its metabolic complications (5).

In human obesity, the metabolic clearance rate of cortisol is increased in the liver, secondary to enhanced cortisol inactivation by A-ring reductases (6) and impaired regeneration of cortisol from cortisone by HSD11B1 (7). However, intra-adipose cortisol generation by HSD11B1 is increased (7). This probably balances the down-regulation of HSD11B1 in the liver (7), as whole-body HSD11B1 activity, measured in vivo by the rate of appearance of trideuterated cortisol $\left(9,12,12-{ }^{2} \mathrm{H}_{3}\right.$-cortisol, d3-cortisol) during tetradeuterated cortisol infusion $(9,11,12,12$ $\left[{ }^{2} \mathrm{H}\right]_{4}$-cortisol, d4-cortisol) (8), is not altered in obesity (9). However, the selective increase in HSD11B1 activity in the adipose tissue seems to contribute to the association between obesity and metabolic complications. Cortisol is pivotal in adipogenesis by promoting the differentiation of stromal cells (preadipocytes to adipocytes) and plays a crucial role in modulating glucose homeostasis, insulin sensitivity, and energy balance $(10,11)$.

Polycystic ovary syndrome (PCOS) is a heterogeneous disorder, characterized by androgen excess, ovulatory dysfunction, and polycystic ovaries. Obesity and insulin resistance are also frequently present and contribute to the pathogenesis of PCOS (12). In addition, women with PCOS frequently develop metabolic dysregulations at early ages, particularly type 2 diabetes (13). One hypothesis to explain the association of obesity with PCOS is that altered cortisol metabolism contributes to the activation of the hypothalamic-pituitary-adrenal axis and induces
ACTH-dependent androgen excess. This has been supported by evidence that women with PCOS excrete a higher proportion of cortisol metabolites in urine as $5 \alpha$ and $5 \beta$-reduced steroids $(14,15,16,17)$, suggesting that liver A-ring reductase activity is enhanced, although the ratio of cortisol:cortisone metabolites is not altered, from which it has been inferred that HSD11B1 is not dysregulated in PCOS. However, some of these studies $(14,15)$ have not distinguished the effects of PCOS from potentially confounding effects of coexistent obesity. Moreover, all these studies have relied on ratios of cortisol metabolites in 24-h urine with inconsistent results $(14,15,16,17,18,19$, 20 ), perhaps explained by complex changes in the balance between many enzymes that influence urinary steroid excretion and by the insensitivity of urinary steroid measurements to detect tissue-specific changes in cortisol metabolism. To assess HSD11B1 activity directly in vivo, a tracer for cortisol regeneration must be used (8).

The purpose of this study was to investigate cortisol metabolism, including whole-body and tissue-specific activities of HSD11B1, in PCOS using the 'gold standard' methods. To do this, cortisol clearance was measured during d4-cortisol infusion; whole-body HSD11B1 activity was measured by the rate of appearance of d3-cortisol during d4-cortisol infusion; hepatic HSD11B1 activity was assessed by measuring conversion of an oral dose of cortisone into cortisol on first-pass metabolism in the liver; and subcutaneous adipose HSD11B1 was assessed, ex vivo, by measuring enzyme activity and mRNA in subcutaneous abdominal fat biopsies. To eliminate the confounding effect of obesity, we matched patients having PCOS with controls for BMI and body fat distribution. In addition, we have recently demonstrated that $H S D 11 B 1$ genotypes influence enzyme activity in vivo (20). In particular, we found that the combination of SNPs rs846910 A and rs12086634 T confers increased HSD11B1 transcript levels in adipose tissue and increased whole-body regeneration of cortisol from cortisone. Therefore, to eliminate the potential confounding effect of HSD11B1 genotypes, we also matched patients having PCOS with controls for the combination of the two SNPs rs846910 and rs12086634.

\section{Subjects and methods}

\section{Study design}

We investigated 20 overweight-obese unmedicated Caucasian Italian women with PCOS, aged 18-45 years, and 20 Caucasian controls matched for age, BMI, body fat 
distribution, estimated by waist circumference and by a computerized tomography (CT) scan at the level of L4-L5 (21), and for HSD11B1 genotypes (rs846910 and rs12086634). Women with PCOS had at least two of the following symptoms: i) chronic oligoovulation-anovulation (luteal serum progesterone below $2 \mathrm{ng} / \mathrm{ml}$ (22)); ii) hirsutism (modified Ferriman-Gallwey score $\geq 8$ (23)) or elevated serum total testosterone levels (24); and iii) polycystic ovarian morphology at ultrasound, according to the Rotterdam consensus conference criteria (25). Hyperprolactinemia, Cushing's syndrome, congenital adrenal hyperplasia, and androgen-secreting tumors were excluded by laboratory analysis (26). Controls had no signs of hyperandrogenism and regular ovulatory menstrual cycles (progesterone levels $\geq 8 \mathrm{ng} / \mathrm{ml}$ during the luteal phase (22)). None of the participants had thyroid dysfunction, cardiovascular, renal, or liver diseases on clinical examination and routine laboratory tests.

These women attended on three further study days. On the first day, they completed a 24-h urine collection and attended at $0800-0830 \mathrm{~h}$ after overnight fast. Basal blood samples for hormonal (luteinizing hormone (LH), androstenedione, DHEA-S, SHBG, cortisol, adiponectin) and metabolic (total cholesterol, HDL cholesterol, triglycerides, ALT, AST, $\gamma \mathrm{GT}$ ) measurements were collected before a $75 \mathrm{~g}$ oral glucose tolerance test (OGTT) with blood samples taken after 30,60, 90, 120, and $180 \mathrm{~min}$ for glucose and insulin determinations. On the same day, fatfree mass and fat mass were estimated with a singlefrequency $50 \mathrm{kHz}$ bioelectrical impedance analyzer (BIA 101 RJL, Akern Bioresearch, Florence, Italy), according to the standard tetrapolar technique, with the subject in supine position and the electrodes placed on the dorsal surface of the right foot and ankle, and the right wrist and hand, and using the software provided by the manufacturer $(27,28)$. On the second day at $0800 \mathrm{~h}$, after overnight fast, a $300 \mathrm{mg}$ s.c. needle aspiration biopsy of subcutaneous adipose tissue from the anterior abdominal wall was obtained and stored at $-80^{\circ} \mathrm{C}$ as described previously (29). After the biopsy procedure, d4-cortisol (Cambridge Isotopes, Andover, MA, USA) was infused at 20 molar percent excess of cortisol (Flebocortid Richer, SanofiAventis S.p.A., Milano, Italy) at $1.74 \mathrm{mg} / \mathrm{h}$ after a priming bolus dose of $3.5 \mathrm{mg}$, and blood sampled at intervals for $4 \mathrm{~h}$ (8). The evening before the third assessment day, subjects took $1 \mathrm{mg}$ oral dexamethasone (Decadron, Visufarma S.p.A., Roma, Italy) at $2300 \mathrm{~h}$, to suppress endogenous cortisol production, and fasted overnight. At $0800 \mathrm{~h}$, an oral dose of $25 \mathrm{mg}$ cortisone acetate (Cortone Acetato, Giuseppe Rende S.r.L., Roma, Italy) was administered and blood samples obtained at intervals for $4 \mathrm{~h}$ to measure plasma cortisol.

Samples were immediately chilled on ice and centrifuged; $24-\mathrm{h}$ urine and serum were stored at $-20{ }^{\circ} \mathrm{C}$ and plasma at $-80^{\circ} \mathrm{C}$. Studies were performed between days 5 and 10 of the menstrual cycle, or during amenorrhea, after excluding pregnancy by appropriate testing. The study protocol was approved by the ethics committee (Ref. $154 / 2005 / \mathrm{U} /$ Sper) and informed consent was obtained from the patients.

\section{Laboratory assays}

Hormone and biochemical assays - The assays for hormonal and biochemical measurements have been reported elsewhere (26). Serum adiponectin was measured by the RIA kit (Linco Research, Inc., St Charles, MO, USA) using ${ }^{125}$ I-labeled adiponectin and polyclonal antiserum. All samples were measured in a single assay. The intraassay coefficient of variation values at low $(12.2 \mathrm{ng} / \mathrm{ml})$ and high $(60.4 \mathrm{ng} / \mathrm{ml})$ levels were 9.7 and $8.5 \%$ respectively. LDL cholesterol was calculated by the Friedewald calculation (30), and the free androgen index (FAI) was calculated as the ratio between total testosterone and SHBG (31). Insulin resistance was estimated using the homeostasis model assessment (HOMA-IR) (32) and the insulin sensitivity index during the OGTT (ISI) (33).

Analysis of d4-cortisol and its metabolites $~$ Plasma d4-cortisol, d3-cortisone, and d3-cortisol were measured by liquid chromatography/tandem mass spectrometry as described previously (34) and tracer kinetics was calculated using the mean of five measurements in steady state between 180 and 240 min of d4-cortisol infusion. The rate of appearance of d3-cortisol was calculated as (d4-cortisol infusion rate)/(d4-cortisol:d3-cortisol ratio). The rate of appearance of cortisol was calculated as ((d4-cortisol infusion rate)/(d4-cortisol:cortisol ratio))-(cortisol infusion rate). Clearance of d4-cortisol was calculated as (d4-cortisol infusion rate)/(d4-cortisol).

Analysis of urinary steroids $>$ Cortisol and its metabolites ( $5 \beta$-tetrahydrocortisol ( $5 \beta$-THF), $5 \alpha$-THF, $5 \beta$-tetrahydrocortisone (5 3 -THE), cortols, cortolones, and cortisone) were measured in urine by electron impact gas chromatography-mass spectrometry (GC-MS) as described previously (20). Total cortisol excretion was calculated from the sum of $5 \beta$-THF, $5 \alpha$-THF, $5 \beta$-THE, cortols, and cortolones. The balance of HSD11B1 and HSD11B2 activities in all tissues was assessed as the ratio of 
$(5 \alpha-\mathrm{THF}+5 \beta-\mathrm{THF}) / 5 \beta-\mathrm{THE}$, and renal HSD11B2 activity was assessed as urinary cortisol:cortisone ratio. Relative $5 \alpha$ - and $5 \beta$-reduction of cortisol was assessed by Ulick's A-ring reduction quotients, $5 \alpha$-THF/cortisol and $5 \beta$-THF/cortisol (35). The balance of $5 \beta$ - and $5 \alpha$-reductases was also assessed by the ratio $5 \beta$-THF: $5 \alpha$-THF.

Analysis of adipose tissue HSD11B1 mRNA and activity Approximately $500 \mathrm{mg}$ of fat were homogenized in $1 \mathrm{ml}$ TRIzol (Invitrogen), RNA was quantified by spectrophotometry, and RNA integrity was checked by agarose gel electrophoresis. RNA of $1 \mu \mathrm{g}$ was reverse transcribed using the Invitrogen Reverse Transcription System and transcript levels of HSD11B1 were quantified by real-time PCR with primer-probes sets from PE Applied Biosystems: 5'-GGAATATTCAGTGTCCAGGGTCAA-3' (forward), 5'-TGATCTCCAGGGCACATTCCT-3' (reverse), and 5'-6-FAM-CTTGGCCTCATAGACACAGAAACAGCCATAMRA-3' (probe). Human cyclophilin A (PE Applied Biosystems) was used to normalize the HSD11B1 transcript levels. A standard curve was generated in triplicate by serial dilution of cDNA pooled from several subjects. Each sample was run in duplicate, and the mean of the duplicates was expressed as a fold difference in RNA level vs an internal control sample. RT negative controls and intron spanning primers were used to demonstrate the lack of genomic DNA contamination and further prevent its amplification respectively.

Adipose tissue HSD11B1 activity was measured in the dehydrogenase direction, which is the more stable in vitro and under conditions of prolonged incubation to obtain measurable conversion with the low available protein concentrations without exhausting substrate supply, as described previously (36). Briefly, $250 \mathrm{mg}$ of tissue were homogenized in KREBS buffer. Total protein of $400 \mu \mathrm{g} / \mathrm{ml}$ was incubated with $2 \mathrm{mM}$ NADP, $0.2 \%$ glucose, and $100 \mathrm{nM}$ cortisol (of which $10 \mathrm{nM}$ is $1,2,6,7-\left[{ }^{3} \mathrm{H}\right]_{4}$-cortisol) at $37^{\circ} \mathrm{C}$ for $30 \mathrm{~h}$. Aliquots were withdrawn at intervals $(6,24$, and $30 \mathrm{~h})$ and conversion to $1,2,6,7-\left[{ }^{3} \mathrm{H}\right]_{4}$-cortisone was measured by HPLC with online scintillation detection. Results are expressed as picomole of product generated per microgram of homogenized tissue.

\section{Statistical analysis}

Data are expressed as means \pm s.E.M. Normal distribution of variables was tested by means of the Kolmogorov-Smirnov test. General linear models were applied in order to analyze data. In particular, multivariate Hotelling's test was applied to groups of homogeneous variables, one-way repeated measures ANOVA was used to compare patients with PCOS and controls, while two-way repeated measures ANOVA was applied to variables evaluated at different time points (i.e. liver and adipose HSD11B1 activities). One-way repeated measures ANCOVA was applied in order to relate subcutaneous adipose tissue HSD11B1 mRNA levels and subcutaneous and liver HSD11B1 activities, expressed as AUC values, with biochemical parameters. No post-hoc analysis was performed. Statistical analyses were performed using the IBM SPSS Statistics (Version 21 for Windows, IBM Co., Armonk, NY, USA) software package. Two-tailed $P<0.05$ were considered statistically significant.

\section{Results}

Women with PCOS and controls were of similar age, BMI, and body fat distribution and had similar plasma transaminases, lipids, and LH and cortisol levels (Table 1). However, as expected, PCOS cases had higher levels of androgens (total testosterone, FAI, androstenedione, and DHEA-S), higher insulin response to the OGTT, and lower levels of adiponectin in plasma when compared with controls (Table 1). In addition, women with PCOS had a higher HOMA-IR and a lower ISI, reflecting lower insulin sensitivity when compared with controls (Table 1).

Cortisol metabolites were measured in urine to assess HSD11B1 activity in vivo (Table 2). Women with PCOS did not differ from controls in terms of $(5 \alpha-\mathrm{THF}+5 \beta-\mathrm{THF}) /$ $5 \beta$-THE ratio, suggesting a similar process of whole-body conversion of cortisone to cortisol. The A-ring reduction quotients reflecting $5 \alpha-(5 \alpha-\mathrm{THF} / \mathrm{cortisol})$ and $5 \beta$-reductase activity (5 $\beta$-THF/cortisol) did not differ between patients with PCOS and controls. Similarly, the $5 \beta$-THF $/ 5 \alpha$-THF ratio, that reflects the balance of $5 \beta$ - and $5 \alpha$-reductases, was similar between PCOS cases and controls.

During d4-cortisol infusion, steady state was achieved between 180 and $240 \mathrm{~min}$. Mean plasma measurements at steady state are given in Table 3. Cortisol, d4-cortisol and d3-cortisone concentrations, and d4-cortisol clearance rate were not different between PCOS cases and controls. Women with PCOS and controls had similar whole-body rates of appearance of cortisol, reflecting the combination of adrenal cortisol secretion and net regeneration of cortisol by HSD11B1, and of d3-cortisol, reflecting exclusively the whole-body contribution of HSD11B1.

Tissue-specific dysregulation of HSD11B1 in PCOS was found. Liver HSD11B1 activity, measured as appearance of cortisol on first-pass conversion after an oral dose of cortisone, was significantly lower in PCOS cases (Fig. 1). 
Table 1 Clinical and biochemical characteristics of PCOS cases and controls. Data are expressed as means \pm s.E.M.

\begin{tabular}{|c|c|c|c|}
\hline Variables & PCOS & Controls & $P$ values \\
\hline Matching design variables & & & $0.98^{a}$ \\
\hline Age (years) & $28.4 \pm 1.6$ & $28.7 \pm 1.4$ & 0.74 \\
\hline BMI $\left(\mathrm{kg} / \mathrm{m}^{2}\right)$ & $35.0 \pm 1.2$ & $34.7 \pm 0.9$ & 0.86 \\
\hline Waist circumference $(\mathrm{cm})$ & $100.9 \pm 2.7$ & $101.3 \pm 2.2$ & 0.92 \\
\hline Body fat (\%) & $42.0 \pm 1.6$ & $40.7 \pm 1.9$ & 0.46 \\
\hline CT scan & & & $0.61^{\mathrm{b}}$ \\
\hline Total adipose tissue $\left(\mathrm{cm}^{2}\right)$ & $584 \pm 45$ & $546 \pm 49$ & 0.81 \\
\hline Subcutaneous adipose tissue $\left(\mathrm{cm}^{2}\right)$ & $483 \pm 37$ & $464 \pm 44$ & 0.97 \\
\hline Visceral adipose tissue $\left(\mathrm{cm}^{2}\right)$ & $101 \pm 11$ & $82 \pm 10$ & 0.70 \\
\hline Visceral:subcutaneous ratio & $0.21 \pm 0.02$ & $0.18 \pm 0.02$ & 0.71 \\
\hline Fasting $0800-0830 \mathrm{~h}$ plasma & & & $<0.05^{\mathrm{a}}$ \\
\hline $\operatorname{ALT}(\mathrm{U} / \mathrm{l})$ & $22.2 \pm 2.7$ & $15.9 \pm 1.0$ & 0.06 \\
\hline AST (U/I) & $30.5 \pm 5.9$ & $19.6 \pm 2.1$ & 0.13 \\
\hline$\gamma \mathrm{GT}(\mathrm{U} / \mathrm{l})$ & $22.7 \pm 3.3$ & $16.9 \pm 2.6$ & 0.20 \\
\hline HDL cholesterol (mmol/l) & $1.35 \pm 0.07$ & $1.53 \pm 0.10$ & 0.09 \\
\hline Triglycerides (mmol/l) & $1.29 \pm 0.13$ & $1.08 \pm 0.12$ & 0.32 \\
\hline LDL cholesterol (mmol/l) & $2.53 \pm 0.19$ & $2.85 \pm 0.20$ & 0.32 \\
\hline Total testosterone $(\mathrm{nmol} / \mathrm{l})$ & $2.27 \pm 0.31$ & $1.04 \pm 0.13$ & $<0.01$ \\
\hline Free androgen index & $3.50 \pm 0.41$ & $1.34 \pm 0.22$ & $<0.001$ \\
\hline Androstenedione (nmol/l) & $13.2 \pm 1.19$ & $6.25 \pm 0.61$ & $<0.001$ \\
\hline DHEA-S $(\mu \mathrm{mol} / \mathrm{l})$ & $6.51 \pm 0.65$ & $3.41 \pm 0.61$ & $<0.01$ \\
\hline $\mathrm{LH}(\mathrm{mU} / \mathrm{ml})$ & $7.50 \pm 1.06$ & $8.68 \pm 1.59$ & 0.81 \\
\hline $\mathrm{SHBG}(\mathrm{mmol} / \mathrm{l})$ & $20.8 \pm 2.4$ & $28.5 \pm 3.3$ & 0.08 \\
\hline Cortisol (nmol/l) & $376 \pm 26$ & $343 \pm 29$ & 0.64 \\
\hline Adiponectin $(\mu \mathrm{g} / \mathrm{ml})$ & $9.84 \pm 0.89$ & $12.03 \pm 1.43$ & $<0.05$ \\
\hline Oral glucose tolerance test & & & $<0.05^{\mathrm{a}}$ \\
\hline Fasting glucose $(\mathrm{mmol} / \mathrm{l})$ & $4.84 \pm 0.32$ & $4.11 \pm 0.09$ & $<0.05$ \\
\hline Fasting insulin $(\mu \mathrm{U} / \mathrm{ml})$ & $21.6 \pm 4.1$ & $13.9 \pm 1.8$ & 0.33 \\
\hline Glucose $_{\text {AUC }}(\mathrm{mmol} / \mathrm{l}$ per min) & $1188 \pm 92$ & $1083 \pm 41$ & 0.17 \\
\hline Insulin $_{\mathrm{AUC}}(\mu \mathrm{IU} / \mathrm{ml}$ per min) & $24296 \pm 5163$ & $12795 \pm 1788$ & $<0.05$ \\
\hline Insulin resistance indices & & & $0.23^{a}$ \\
\hline HOMA-IR & $4.98 \pm 1.09$ & $2.58 \pm 0.36$ & $<0.05$ \\
\hline ISI & $3.30 \pm 0.62$ & $4.79 \pm 0.65$ & $<0.05$ \\
\hline Adipose HSD11B1 mRNA ${ }^{c}$ & $-0.129 \pm 0.072$ & $-0.401 \pm 0.056$ & $<0.05$ \\
\hline
\end{tabular}

${ }^{\text {a}}$ Hotelling's multivariate tests of significance (all parameters).

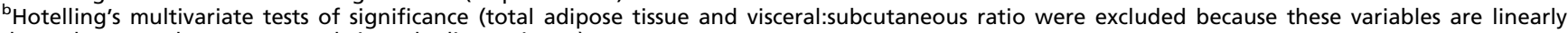
dependent on subcutaneous and visceral adipose tissues).

Expressed as a difference to cyclophilin internal control.

By contrast, in subcutaneous abdominal adipose tissue, both HSD11B1 mRNA levels (Table 1 and Fig. 2A) and 11 $\beta$ HSD1 activity, measured ex vivo by the conversion of cortisone from cortisol (Fig. 2B), were significantly higher in PCOS cases when compared with controls.

The AUC of liver HSD11B1 activity was $60338 \pm$ $6409 \mathrm{nmol} / \mathrm{l}$ per min for PCOS cases and $86935 \pm$ $10211 \mathrm{nmol} / \mathrm{l}$ per min for controls, whereas the AUC of ex vivo $11 \beta$-HSD1 activity in subcutaneous fat was $271 \pm$ $41 \mathrm{pmol} / \mu \mathrm{g}$.h for PCOS cases and $152 \pm 30 \mathrm{pmol} / \mu \mathrm{g}$.h for controls. These were used to perform the one-way ANCOVA of liver and adipose HSD11B1 activities and adipose HSD11B1 mRNA adjusted for biochemical parameters was significantly different between PCOS cases and controls as covariates and the regression analysis (Table 4). In the one-way ANCOVA, liver HSD11B1 activity persisted lower in PCOS cases when compared with controls only after the adjustment for total testosterone and androstenedione, and adipose HSD11B1 activity persisted higher in PCOS cases when compared with controls only after the adjustment for FAI and androstenedione. HSD11B1 mRNA persisted higher in PCOS cases when compared with controls only after the adjustment for androstenedione. In regression analysis, liver HSD11B1 activity and subcutaneous adipose tissue HSD11B1 expression and activity did not correlate significantly with any parameter investigated within controls (Table 4). However, within PCOS, liver HSD11B1 activity correlated negatively with total testosterone, subcutaneous adipose tissue HSD11B1 mRNA levels correlated positively with total testosterone and HOMA-IR, and ex vivo HSD11B1 activity in subcutaneous 
Table 2 24-h urine cortisol metabolites of PCOS cases and controls (Hotelling's multivariate tests of significance, $P<0.05^{\mathrm{a}}$ ). Data are expressed as means \pm s.E.M.

\begin{tabular}{l}
\hline Variables \\
\hline Cortisol ( $\mu$ g/day) \\
Cortisone $(\mu \mathrm{g} /$ day) \\
$5 \beta$-Tetrahydrocortisol $(5 \beta-\mathrm{THF}, \mu \mathrm{g} /$ day $)$ \\
$5 \alpha$-Tetrahydrocortisol $(5 \alpha-\mathrm{THF}, \mu \mathrm{g} /$ day) \\
$5 \beta$-Tetrahydrocortisone $(5 \beta-\mathrm{THE}, \mu \mathrm{g} /$ day $)$ \\
Total cortisol metabolites $(\mu \mathrm{g} / \text { day })^{\mathrm{b}}$ \\
Cortisol/cortisone \\
$(5 \alpha-\mathrm{THF}+5 \beta-\mathrm{THF}) / 5 \beta-\mathrm{THE}$ \\
$5 \alpha-\mathrm{THF} /$ cortisol \\
$5 \beta-\mathrm{THF} /$ cortisol \\
$5 \beta-\mathrm{THF} / 5 \alpha-\mathrm{THF}$
\end{tabular}

\begin{tabular}{c}
\hline PCOS \\
\hline $127 \pm 12$ \\
$188 \pm 20$ \\
$2394 \pm 304$ \\
$2170 \pm 351$ \\
$4572 \pm 606$ \\
$13811 \pm 1489$ \\
$0.774 \pm 0.085$ \\
$1.10 \pm 0.10$ \\
$17.6 \pm 2.7$ \\
$19.8 \pm 2.1$ \\
$1.80 \pm 0.45$
\end{tabular}

\begin{tabular}{c}
\hline Controls \\
\hline $142 \pm 13$ \\
$264 \pm 27$ \\
$2200 \pm 199$ \\
$2716 \pm 365$ \\
$3657 \pm 377$ \\
$13938 \pm 1259$ \\
$0.595 \pm 0.051$ \\
$1.70 \pm 0.46$ \\
$19.6 \pm 2.1$ \\
$16.8 \pm 1.6$ \\
$0.99 \pm 0.11$
\end{tabular}

\begin{tabular}{r}
\hline $\boldsymbol{P}$ values \\
\hline 0.48 \\
$<0.05$ \\
0.66 \\
0.37 \\
0.29 \\
0.96 \\
0.06 \\
0.21 \\
0.61 \\
0.29 \\
0.08
\end{tabular}

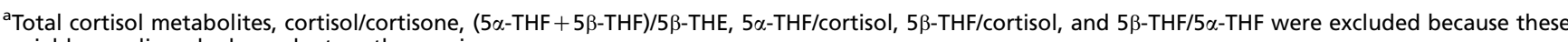
variables are linearly dependent on the previous ones.

${ }^{\mathrm{b}}$ Total cortisol metabolites $=5 \beta-\mathrm{THF}+5 \alpha-\mathrm{THF}+5 \beta-\mathrm{THE}+$ cortols + cortolones.

fat correlated positively with insulin response to the OGTT and with androstenedione. No other significant correlations were found with subcutaneous adipose tissue HSD11B1 mRNA levels or ex vivo HSD11B1 activity (Table 4).

\section{Discussion}

This is the first study to undertake comprehensive functional evaluation of HSD11B1 activity in overweight-obese women with PCOS and weight-matched controls. The novelty of this study is the method used to analyze the in vivo overall activity of HSD11B1 and the measurement of tissue-specific activities of HSD11B1 in PCOS. We found that the overall activity of HSD11B1 in PCOS is similar to that of controls, thus confirming previous results $(14,15,20)$. However, to measure the whole-body activity of $11 \beta$-HSD1, we used not only ratios of cortisol metabolites in 24-h urine, a method used in all the studies performed so far, but also d4-cortisol infusion test, that is the 'gold standard' method, because it is able to discriminate the activity of 11ß-HSD1 from the activities of 11ß-HSD type 2 and A-ring reductases. In addition, we confirmed in this study what was previously demonstrated by others (37), in particular that transcript levels of $H S D 11 B 1$ in subcutaneous adipose tissue are increased in PCOS cases when compared with controls. However, we added for the first time information about subcutaneous HSD11B1 adipose tissue activity, which was increased in PCOS cases, and about hepatic HSD11B1 activity, which was decreased in PCOS cases when compared with controls. The availability of a control group matched for body fat makes it possible to conclude that these differences cannot be attributed to obesity. Therefore, the data reveal that alterations in cortisol metabolism in PCOS do exist and include increased HSD11B1 activity in adipose tissue and decreased HSD11B1 activity in liver, albeit that these alterations appear to be balanced such that whole-body HSD11B1 activity is not measurably altered.

By contrast, in this group of women with PCOS, there was no evidence of the previously reported increase in activities of the A-ring reductases $(14,15,17,18), 5 \beta$ - and

Table 3 Steady-state concentrations and ratios during d4-cortisol infusion in PCOS cases and controls (Hotellings multivariate tests of significance, $P=0.39^{\mathrm{a}}$ ). Data are expressed as means \pm S.E.M. The mean data for each participant from samples obtained between 180 and 240 min during the d4-cortisol infusion was used to calculate steady-state concentrations.

\begin{tabular}{|c|c|c|c|}
\hline Variables & Pcos & Controls & values \\
\hline Cortisol (nmol/l) & $228.2 \pm 23.6$ & $259.9 \pm 42.4$ & 0.52 \\
\hline D4-cortisol (nmol/l) & $38.8 \pm 4.9$ & $42.1 \pm 7.0$ & 0.71 \\
\hline $\begin{array}{l}\text { D4-cortisol clearance } \\
\text { (l/min) }\end{array}$ & $0.575 \pm 0.114$ & $0.502 \pm 0.054$ & 0.56 \\
\hline D4-cortisol:cortisol ratio & $0.177 \pm 0.012$ & $0.176 \pm 0.013$ & 0.94 \\
\hline $\begin{array}{l}\text { D4-cortisol:d3-cortisol } \\
\text { ratio }\end{array}$ & $1.31 \pm 0.08$ & $1.32 \pm 0.07$ & 0.95 \\
\hline D3-cortisone (nmol/l) & $6.70 \pm 0.78$ & $5.42 \pm 0.59$ & 0.18 \\
\hline $\begin{array}{l}\text { Rate of appearance of } \\
\text { cortisol }(\mathrm{nmol} / \mathrm{min})\end{array}$ & $31.4 \pm 9.3$ & $32.7 \pm 9.1$ & 0.93 \\
\hline $\begin{array}{l}\text { Rate of appearance of } \\
\text { d3-cortisol } \\
\text { (nmol/min) }\end{array}$ & $12.1 \pm 0.7$ & $12.1 \pm 0.8$ & 0.99 \\
\hline
\end{tabular}

${ }^{a}$ D4-cortisol:cortisol ratio and d4-cortisol:d3-cortisol ratio were excluded because these variables are linearly dependent on the previous ones. 


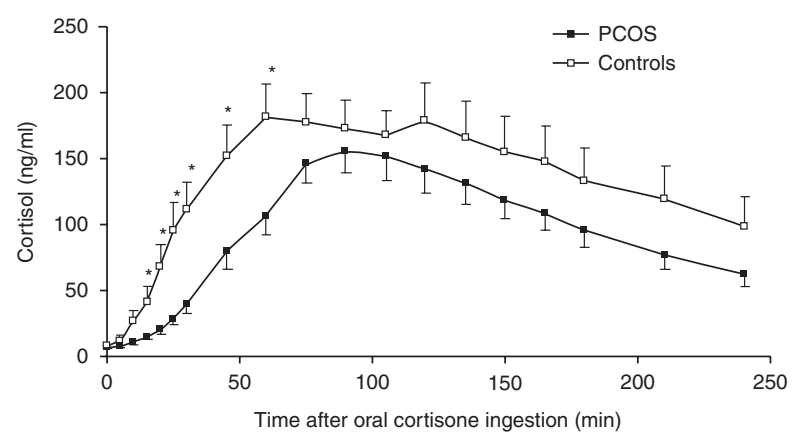

\section{Figure 1}

Liver HSD11B1 activity in PCOS cases and controls. Data are expressed as mean \pm S.E.M. Patients with PCOS (closed square). Controls (open square). By repeated measures ANOVA, PCOS had an overall lower liver HSD11B1 activity $(P<0.05)$. ${ }^{*} P<0.05$ between PCOS and controls at each time point.

$5 \alpha$-reductase, and no change in cortisol clearance. Confounding effects of obesity and/or reliance on urinary steroid ratios, which may be unreliable because they are influenced by the activity of other enzymes, could explain inconsistencies in previous studies $(14,15,16,17$, $18,19,20)$.

Whole-body regeneration of cortisol by HSD11B1 can be measured specifically using the d4-cortisol stable isotope tracer $(8,34)$. Consistent with the lack of difference in urinary cortisol:cortisone metabolite ratios, the rate of appearance of d3-cortisol was similar in our population of women with PCOS when compared with controls, thus demonstrating that whole-body HSD11B1 activity is not altered in overweight-obese women with PCOS. However, in obesity, a similar lack of change in whole-body HSD11B1 activity (9) is accompanied by substantial tissue-specific changes in cortisol regeneration by HSD11B1 $(1,36)$. The major source of extra-adrenal cortisol regeneration is the liver $(2,38)$, but recent data have confirmed that there is a contribution from adipose tissue (34). In this study, we quantified liver HSD11B1 activity by administering oral cortisone and measuring the initial rate of appearance of cortisol in peripheral plasma after first-pass hepatic metabolism (38). This test has potential limitations, because levels of cortisol in plasma reflect not only the amount generated from cortisone by HSD11B1 activity but also the extent of inactivation and clearance of cortisol by $5 \alpha$ - and $5 \beta$-reductases in the liver. However, measurement of the rate of appearance of cortisol in plasma during the early time points (up to $30 \mathrm{~min}$ ) after cortisone ingestion has been validated by measurements of tracer dilution in the hepatic vein, at least in healthy subjects (38). Although similar validation has not been undertaken in patients with PCOS, our data suggest that overweight-obese women with PCOS are characterized by a decrease in HSD11B1 activity in the liver when compared with weight-matched controls. In subcutaneous adipose tissue, the same women were characterized by higher HSD11B1 transcript levels and a higher enzyme activity, measured ex vivo. Similar results for adipose tissue transcript levels of HSD11B1 were previously observed in omental adipose tissue obtained during bariatric surgery of obese women with and without PCOS (39) and in subcutaneous adipose tissue obtained from lean patients with PCOS compared with
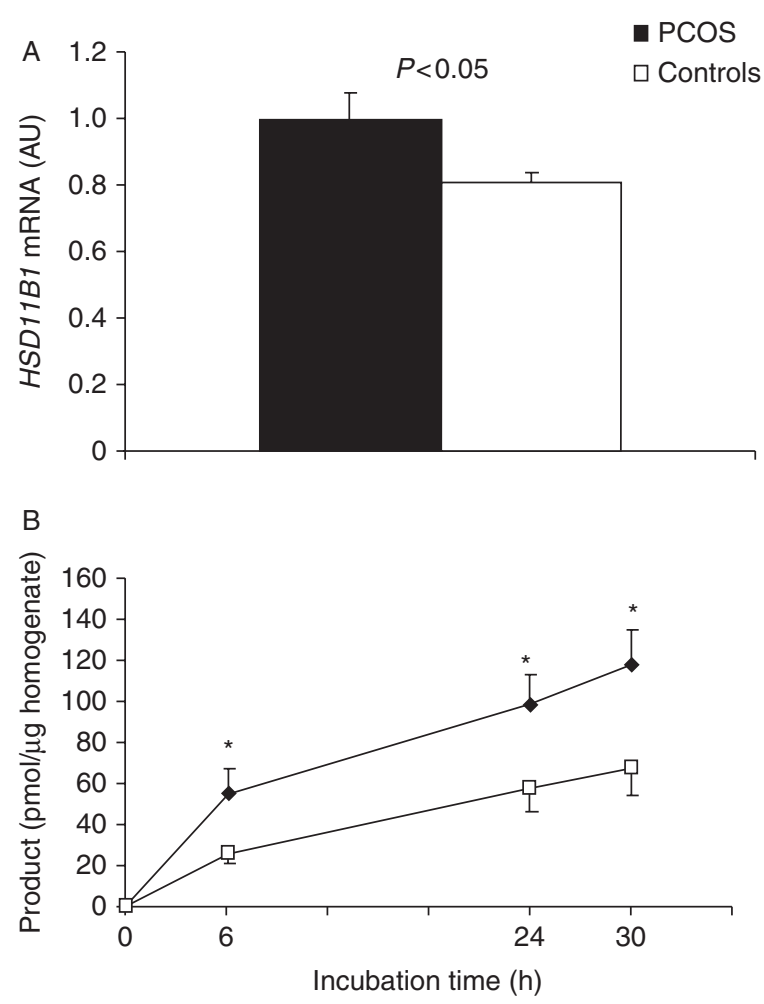

\section{Figure 2}

Adipose HSD11B1 in PCOS cases and controls. Data are expressed as mean \pm s.E.M. (A) HSD11B1 mRNA levels in subcutaneous adipose tissue, expressed as a ratio to cyclophilin internal control. By ANOVA, PCOS had increased transcript levels of HSD11B1 $(P<0.05)$. (B) Ex vivo HSD11B1 activity in subcutaneous adipose tissue, expressed as conversion of cortisol to cortisone. By repeated measures ANOVA, PCOS had a higher HSD11B1 activity $(P<0.05)$. ${ }^{*}<0.05$ between PCOS and controls at each time point. 
Table 4 Results of one-way ANCOVA of liver and adipose HSD11B1 activities and adipose HSD11B1 mRNA adjusted for different biochemical parameters as covariates. The $P$ values of the various effects taken into account are shown in the table. The positive or negative relationships are also indicated within parentheses.

\begin{tabular}{|c|c|c|c|c|}
\hline Covariate & $\begin{array}{l}\text { PCOS vs controls } \\
\text { adjusted for regression }\end{array}$ & $\begin{array}{l}\text { Regression } \\
\text { within PCOS }\end{array}$ & $\begin{array}{c}\text { Regression } \\
\text { within controls }\end{array}$ & $\begin{array}{l}\text { Interaction: regression } \\
\text { within PCOS vs } \\
\text { regression within } \\
\text { controls }\end{array}$ \\
\hline \multicolumn{5}{|l|}{ Liver HSD11B1 activity } \\
\hline Total testosterone & $<0.05$ & $<0.05(-)$ & $0.43(-)$ & 0.18 \\
\hline Free androgen index & 0.09 & $0.70(-)$ & $0.13(-)$ & 0.17 \\
\hline Androstenedione & $<0.05$ & $0.07(-)$ & $0.30(-)$ & 0.13 \\
\hline DHEA-S & 0.30 & $0.10(-)$ & $0.77(-)$ & 0.18 \\
\hline Adiponectin & 0.97 & $0.38(-)$ & $0.69(-)$ & 0.35 \\
\hline Fasting glucose & 0.99 & $0.12(-)$ & $0.75(-)$ & 0.89 \\
\hline Insulin $\mathrm{AUC}$ & 0.37 & $0.83(-)$ & $0.64(-)$ & 0.74 \\
\hline HOMA-IR & 0.64 & $0.73(+)$ & $0.44(+)$ & 0.49 \\
\hline ISI & 0.20 & $0.64(+)$ & $0.71(-)$ & 0.57 \\
\hline \multicolumn{5}{|c|}{ Adipose HSD11B1 activity $^{a}$} \\
\hline Total testosterone & 0.13 & $0.44(+)$ & $0.74(+)$ & 0.56 \\
\hline Free androgen index & $<0.05$ & $0.29(+)$ & $0.16(+)$ & 0.16 \\
\hline Androstenedione & $<0.01$ & $<0.05(+)$ & $0.29(+)$ & 0.05 \\
\hline DHEA-S & 0.06 & $0.10(-)$ & $0.35(-)$ & 0.46 \\
\hline Adiponectin & 0.19 & $0.84(+)$ & $0.72(+)$ & 0.57 \\
\hline Fasting glucose & 0.68 & $0.25(+)$ & $0.33(+)$ & 0.81 \\
\hline Insulin $\mathrm{AUC}$ & 0.60 & $<0.05(+)$ & $0.54(+)$ & 0.88 \\
\hline HOMA-IR & 0.74 & $0.39(+)$ & $0.53(-)$ & 0.39 \\
\hline ISI & 0.38 & $0.40(-)$ & $0.67(-)$ & 0.67 \\
\hline \multicolumn{5}{|c|}{ Adipose HSD11B1 mRNA ${ }^{b}$} \\
\hline Total testosterone & 0.57 & $<0.05(+)$ & $0.59(+)$ & 0.06 \\
\hline Free androgen index & 0.33 & $0.57(+)$ & $0.99(+)$ & 0.81 \\
\hline Androstenedione & $<0.05$ & $0.15(+)$ & $0.16(+)$ & 0.09 \\
\hline DHEA-S & 0.69 & $0.35(-)$ & $0.89(-)$ & 0.07 \\
\hline Adiponectin & 0.65 & $0.32(-)$ & $0.13(-)$ & 0.99 \\
\hline Fasting glucose & 0.39 & $0.77(+)$ & $0.44(+)$ & 0.49 \\
\hline Insulin $_{A \cup C}$ & 0.11 & $0.96(+)$ & $0.17(+)$ & 0.26 \\
\hline HOMA-IR & 0.26 & $<0.05(+)$ & $0.40(+)$ & 0.61 \\
\hline ISI & 0.44 & $0.22(-)$ & $0.35(-)$ & 0.63 \\
\hline
\end{tabular}

${ }^{a}$ Ex-vivo HSD11B1 activity in subcutaneous adipose tissue, expressed as conversion of cortisol to cortisone.

${ }^{\mathrm{b}}$ HSD11B1 mRNA levels in subcutaneous adipose tissue, expressed as a ratio to cyclophilin internal control.

lean controls (37). Overall, these data show that the tissue-specific dysregulation of HSD11B1, well established in obesity in rodents and humans $(1,36)$, is also observed in women with PCOS compared with weightmatched controls.

Previous studies have described increased excretion of $5 \alpha$ - or $5 \beta$-reduced cortisol metabolites in urine and inferred that increased cortisol clearance might impair negative feedback suppression of the hypothalamicpituitary-adrenal axis, thereby contributing to ACTHdependent adrenal androgen excess $(16,17)$. However, our data suggest that there is no added effect of PCOS on cortisol clearance or on urinary cortisol metabolite excretion over and above the presence of obesity. Increased cortisol clearance is a consistent finding with obesity $(9,40,41)$, but our data suggest that it is not a feature of PCOS per se. However, the results relying on cortisol metabolites in the urine have to be considered with caution because they are influenced by the activity of many enzymes.

The cross-sectional design of the study does not allow us to evaluate what it is about PCOS that causes changes of HSD11B1 over and above obesity. However, we can speculate that two factors might be involved: insulin and androgens. In humans, insulin infusion acutely increases intra-adipose HSD11B1 activity, probably through a posttranscriptional mechanism $(42,43)$. A stimulatory effect of insulin on adipocyte HSD11B1 that involves activation of the p38 MAPK signaling pathway has been demonstrated (44). In addition, insulin decreases HSD11B1 in hepatocytes in vitro (45) while, in vivo, a reduction of fasting insulin concentration by a low-carbohydrate diet is 
associated with an increased hepatic HSD11B1 activity (29). Therefore, chronic hyperinsulinemia, as so frequently observed in PCOS, particularly in the overweight-obese phenotype (12), might be responsible for both increased adipose $11 \beta$-HSD1 and decreased hepatic HSD11B1 activities. Accordingly, we found a positive correlation between subcutaneous HSD11B1 mRNA expression and HOMA-IR and between subcutaneous HSD11B1 activity and insulin responsiveness to the glucose load. These findings, in particular that subcutaneous HSD11B1 expression and activity in humans is negatively correlated with insulin sensitivity, are consistent with previous observations in the general population (46) and in PCOS cases (37). Increased activity of adipose HSD11B1 in PCOS could also reflect a regulatory effect of androgen excess; it has been demonstrated that testosterone induces the expression and activity of intraadipose HSD11B1 in humans, in omental more than subcutaneous depots (47). Indeed, we found a positive correlation between androstenedione and subcutaneous HSD11B1 activity in PCOS. In addition, we found a negative correlation between testosterone and liver HSD11B1 activity, consistent with an inhibitory effect of androgens on hepatic HSD11B1.

It is impossible from this observational study to establish whether these alterations in cortisol metabolism are primary or secondary to the development of PCOS. On one hand, increased intra-adipose cortisol production due to primary HSD11B1 overactivity could induce the differentiation of adipose stromal cells to adipocytes, particularly in visceral depots, with a consequent increase in visceral adiposity, and the development of insulin resistance and hyperinsulinemia. On the other hand, testosterone-induced up-regulation of HSD11B1 could increase intra-adipose cortisol regeneration, with a consequent increased preadipocyte differentiation and amplification of the negative effect of excess body fat on the PCOS phenotype.

In conclusion, PCOS-specific overactivity of HSD11B1 within adipose tissue could influence fat distribution, contribute to metabolic consequences, and perpetuate the syndrome. These findings reinforce the importance of HSD11B1 as a pathophysiological mediator in PCOS and suggest that approaches aimed at reducing glucocorticoid action in adipose tissue in this condition may be valuable.

Declaration of interest

The authors declare that there is no conflict of interest that could be perceived as prejudicing the impartiality of the research reported.
Funding

This work was supported by the British Heart Foundation ( $R$ Andrew, B R Walker).

\section{Author contribution statement}

A Gambineri contributed to data acquisition, revision, and interpretation, drafted and critically revised the article, and wrote and approved the final version of the manuscript. F Fanelli, F Tomassoni, A Munarini, and $\mathrm{R}$ Andrew performed laboratory analysis, critically revised the article for intellectual content, and approved the final version of the manuscript. B R Walker, and R Pasquali contributed to data revision and interpretation, drafted and critically revised the article, and wrote and approved the final version of the manuscript.

\section{Acknowledgements}

We are grateful to the staff of the Mass Spectrometry Core Laboratory of the Wellcome Trust Clinical Research Facility in Edinburgh for their support with assays.

\section{References}

1 Seckl JR \& Walker BR. Minireview: 11 $\beta$-hydroxysteroid dehydrogenase type 1-a tissue-specific amplifier of glucocorticoid action. Endocrinology 2001142 1371-1376.

2 Basu R, Singh RJ, Basu A, Chittilapilly EG, Johnson CM, Toffolo G, Cobelli C \& Rizza RA. Splanchnic cortisol production occurs in humans - evidence for conversion of cortisone to cortisol via the 11- $\beta$ hydroxysteroid dehydrogenase type 1 pathway. Diabetes 200453 2051-2059. (doi:10.2337/diabetes.53.8.2051)

3 Masuzaki H, Paterson J, Shinyama H, Morton NM, Mullins JJ, Seckl JR \& Flier JS. A transgenic model of visceral obesity and the metabolic syndrome. Science 2001294 2166-2170. (doi:10.1126/science.1066285)

4 Paterson JM, Morton NM, Fievet C, Kenyon CJ, Holmes MC, Staels B, Seckl JR \& Mullins JJ. Metabolic syndrome without obesity: hepatic overexpression of $11 \beta$-hydroxysteroid dehydrogenase type 1 in transgenic mice. PNAS 2004101 7088-7093. (doi:10.1073/pnas. 0305524101)

5 Morton NM, Holmes MC, Fievet C, Staels B, Tailleux A, Mullins JJ \& Seckl JR. Improved lipid and lipoprotein profile, hepatic insulin sensitivity, and glucose tolerance in $11 \beta$-hydroxysteroid dehydrogenase type 1 null mice. Journal of Biological Chemistry 2001276 41293-41300. (doi:10.1074/jbc.M103676200)

6 Andrew R, Phillips DI \& Walker BR. Obesity and gender influence cortisol secretion and metabolism in man. Journal of Clinical Endocrinology and Metabolism 199883 1806-1809. (doi:10.1210/jcem.83.5.4951)

7 Rask E, Walker BR, Soderberg S, Livingstone DE, Eliasson M, Johnson O, Andrew R \& Olsson T. Tissue-specific changes in peripheral cortisol metabolism in obese women: increased adipose $11 \beta$-hydroxysteroid dehydrogenase type 1 activity. Journal of Clinical Endocrinology and Metabolism 200287 3330-3336.

8 Andrew R, Smith K, Jones GC \& Walker BR. Distinguishing the activities of 11ß-hydroxysteroid dehydrogenases in vivo using isotopically labelled cortisol. Journal of Clinical Endocrinology and Metabolism 2002 87 277-285.

9 Sandeep TC, Andrew R, Homer NZ, Andrews RC, Smith K \& Walker BR. Increased in vivo regeneration of cortisol in adipose tissue in human obesity and effects of the $11 \beta$-hydroxysteroid dehydrogenase type 1 inhibitor carbenoxolone. Diabetes 200554 872-879. (doi:10.2337/ diabetes.54.3.872) 
10 Bujalska IJ, Walker EA, Hewison M \& Stewart PM. A switch in dehydrogenase to reductase activity of $11 \beta$-hydroxysteroid dehydrogenase type 1 upon differentiation of human omental adipose stromal cells. Journal of Clinical Endocrinology and Metabolism 200287 1205-1210.

11 Bujalska IJ, Kumar S, Hewison M \& Stewart PM. Differentiation of adipose stromal cells: the roles of glucocorticoids and 11ß-hydroxysteroid dehydrogenase. Endocrinology 1999140 3188-3196.

12 Randeva HS, Tan BK, Weickert MO, Lois K, Nestler JE, Sattar N \& Lehnert H. Cardiometabolic aspects of the polycystic ovary syndrome. Endocrine Reviews 201233 812-841. (doi:10.1210/er.2012-1003)

13 Gambineri A, Patton L, Altieri P, Pagotto U, Pizzi C, Manzoli L \& Pasquali R. Polycystic ovary syndrome is a risk factor for type 2 diabetes: results from a long-term prospective study. Diabetes $2012 \mathbf{6 1}$ 2369-2374. (doi:10.2337/db11-1360)

14 Stewart PM, Shackleton CH, Beastall GH \& Edwards CR. $5 \alpha$-reductase activity in polycystic ovarian syndrome. Lancet 1990335 431-433. (doi:10.1016/0140-6736(90)90664-Q)

15 Chin D, Shackleton C, Prasad VK, Kohn B, David R, ImperatoMcGinley J, Cohen H, McMahon DJ \& Oberfield SE. Increased $5 \alpha$-reductase and normal $11 \beta$-hydroxysteroid dehydrogenase metabolism of C19 and C21 steroids in a young population with polycystic ovarian syndrome. Journal of Pediatric Endocrinology \& Metabolism 200013 253-259. (doi:10.1515/JPEM.2000.13.3.253)

16 Gambineri A, Forlani G, Munarini A, Tomassoni F, Cognigni GE, Ciampaglia W, Pagotto U, Walker BR \& Pasquali R. Increased clearance of cortisol by $5 \beta$-reductase in a subgroup of women with adrenal hyperandrogenism in polycystic ovary syndrome. Journal of Endocrinological Investigation 200932 210-218. (doi:10.1007/BF03346454)

17 Vassiliadi DA, Barber TM, Hughes BA, McCarthy MI, Wass JA, Franks S, Nightingale P, Tomlinson JW, Arlt W \& Stewart PM. Increased $5 \alpha$-reductase activity and adrenocortical drive in women with polycystic ovary syndrome. Journal of Clinical Endocrinology and Metabolism 200994 3558-3566. (doi:10.1210/jc.2009-0837)

18 Rodin A, Thakkar H, Taylor N \& Clayton R. Hyperandrogenism in polycystic ovary syndrome: evidence of dysregulation of $11 \beta$-hydroxysteroid dehydrogenase. New England Journal of Medicine 1994330 460-465. (doi:10.1056/NEJM199402173300703)

19 Tsilchorozidou T, Honour JW \& Conway GS. Altered cortisol metabolism in polycystic ovary syndrome: insulin enhances $5 \alpha$-reduction but not the elevated adrenal steroid production rates. Journal of Clinical Endocrinology and Metabolism 200388 5907-5913. (doi:10.1210/jc.2003-030240)

20 Gambineri A, Tomassoni F, Munarini A, Stimson RH, Mioni R, Pagotto U, Chapman KE, Andrew R, Mantovani V, Pasquali R et al. A combination of polymorphisms in HSD11B1 associates with in vivo $11 \beta-H S D 1$ activity and metabolic syndrome in women with and without polycystic ovary syndrome. European Journal of Endocrinology 2011165 283-292. (doi:10.1530/EJE-11-0091)

21 Gambineri A, Patton L, Vaccina A, Cacciari M, Morselli-Labate AM, Cavazza C, Pagotto U \& Pasquali R. Treatment with flutamide, metformin, and their combination added to a hypocaloric diet in overweight-obese women with polycystic ovary syndrome: a randomized, 12-month, placebo-controlled study. Journal of Clinical Endocrinology and Metabolism 200691 3970-3980. (doi:10.1210/jc. 2005-2250)

22 Nestler JE, Jakubowicz DJ, Evans WS \& Pasquali R. Effects of metformin on spontaneous and clomiphene-induced ovulation in the polycystic ovary syndrome. New England Journal of Medicine 1998338 1876-1880. (doi:10.1056/NEJM199806253382603)

23 Hatch R, Rosenfield RL, Kim MH \& Tredway D. Hirsutism: implications, etiology, and management. American Journal of Obstetrics and Gynecology 1981140 815-830.

24 Gambineri A, Pelusi C, Genghini S, Morselli-Labate AM, Cacciari M, Pagotto U \& Pasquali R. Effect of flutamide and metformin administered alone or in combination in dieting obese women with polycystic ovary syndrome. Clinical Endocrinology 200460 241-249. (doi:10.1111/ j.1365-2265.2004.01973.x)

25 The Rotterdam ESHRE/ASMR-sponsored PCOS consensus workshop group. Revised 2003 consensus on diagnostic criteria and long-term health risks related to polycystic ovary syndrome. Human Reproduction 200419 41-47. (doi:10.1093/humrep/deh098)

26 Pasquali R, Gambineri A, Biscotti D, Vicennati V, Gagliardi L, Colitta D, Fiorini S, Cognigni GE, Filicori M \& Morselli-Labate AM. Effect of longterm treatment with metformin added to hypocaloric diet on body composition, fat distribution, and androgen and insulin levels in abdominally obese women with and without the polycystic ovary syndrome. Journal of Clinical Endocrinology and Metabolism 200085 2767-2774. (doi:10.1210/jcem.85.8.6738)

27 Talluri T, Lietdke RJ, Evangelisti A, Talluri J \& Maggia G. Fat-free mass qualitative assessment with bioelectric impedance analysis (BIA). Annals of the New York Academy of Sciences 1999873 94-98. (doi:10.1111/j.1749-6632.1999.tb09454.x)

28 Piccoli A, Nigrelli S, Caberlotto A, Bottazzo S, Rossi B, Pillon L \& Maggiore Q. Bivariate normal values of the bioelectrical impedance vector in adult and elderly populations. American Journal of Clinical Nutrition 199561 269-270.

29 Stimson RH, Johnstone AM, Homer NZ, Wake DJ, Morton NM, Andrew R, Lobley GE \& Walker BR. Dietary macronutrient content alters cortisol metabolism independently of body weight changes in obese men. Journal of Clinical Endocrinology and Metabolism 200792 4480-4484. (doi:10.1210/jc.2007-0692)

30 Friedewald WT, Levy RI \& Fredrickson DS. Estimation of the concentration of low-density lipoprotein cholesterol in plasma, without use of the preparative ultracentrifuge. Clinical Chemistry 197218 499-502.

31 Vermeulen A, Verdonck L \& Kaufman JM. A critical evaluation of simple methods for the estimation of free testosterone in serum. Journal of Clinical Endocrinology and Metabolism 199984 3666-3672. (doi:10.1210/jcem.84.10.6079)

32 Matthews DR, Hosker IP, Rudenski AS, Naylor BA, Treacher DF \& Turner RC. Homeostasis model assessment: insulin resistance and $\beta$-cell function from fasting plasma glucose and insulin concentrations in man. Diabetologia 198528 412-419. (doi:10.1007/BF00280883)

33 Matsuda M \& DeFronzo RA. Insulin sensitivity indices obtained from oral glucose tolerance testing: comparison with the euglycemic insulin clamp. Diabetes Care 199922 1462-1470. (doi:10.2337/diacare. 22.9.1462)

34 Stimson RH, Andersson J, Andrew R, Redhead DN, Karpe F, Hayes PC, Olsson T \& Walker BR. Cortisol release from adipose tissue by $11 \beta$-hydroxysteroid dehydrogenase type 1 in humans. Diabetes $2009 \mathbf{5 8}$ 46-53. (doi:10.2337/db08-0969)

35 Ulick S, Tedde R \& Wang JZ. Defective ring A reduction of cortisol as the major metabolic error in the syndrome of apparent mineralocorticoid excess. Journal of Clinical Endocrinology and Metabolism $1992 \mathbf{7 4}$ 593-599.

36 Rask E, Olsson T, Soderberg S, Andrew R, Livingstone DEW, Johnson O $\&$ Walker BR. Tissue-specific dysregulation of cortisol metabolism in human obesity. Journal of Clinical Endocrinology and Metabolism 200186 1418-1421. (doi:10.1210/jcem.86.3.7453)

37 Svedsen PF, Madsbad S, Nilas L, Paulsen SK \& Pedersen SB. Expression of 11ß-hydroxysteroid dehydrogenase 1 and 2 in subcutaneous adipose tissue of lean and obese women with and without polycystic ovary syndrome. International Journal of Obesity 200933 1249-1256. (doi:10.1038/ijo.2009.165)

38 Andrew R, Westerbacka J, Wahren J, Yki-Jarvinen H \& Walker BR. The contribution of visceral adipose tissue to splanchnic cortisol production in healthy humans. Diabetes $2005 \mathbf{5 4} 1364-1370$. (doi:10.2337/diabetes.54.5.1364)

39 Corton M, Botella-Carrettero JI, Benguria A, Villuendas G, Zaballos A, San Millan JL, Escobar-Morreale HF \& Peral B. Differential gene expression profile in omental adipose tissue in women with polycystic 
ovary syndrome. Journal of Clinical Endocrinology and Metabolism 2007 92 328-337. (doi:10.1210/jc.2006-1665)

40 Strain GW, Zumoff B \& Strain JJ. Cortisol production in obesity. Metabolism: Clinical and Experimental 198029 980-985. (doi:10.1016/ 0026-0495(80)90043-8)

41 Lottenberg SA, Giannella-Neto D, Derendorf H, Rocha M, Bosco A, Carvalho SV, Moretti AE, Lerario AC \& Wajchenberg BL. Effect of fat distribution on the pharmacokinetics of cortisol in obesity. International Journal of Clinical Pharmacology and Therapeutics 199836 501-505.

42 Westerbacka J, Cornér A, Kannisto K, Kolak M, Makkonen J, Korsheninnikova E, Nyman T, Hamsten A, Fisher RM \& Yhi-Järvinen H. Acute in vivo effects of insulin on gene expression in adipose tissue in insulin-resistant and insulin-sensitive subjects. Diabetologia 200649 132-140. (doi:10.1007/s00125-005-0075-5)

43 Wake DJ, Homer NZ, Andrew R \& Walker BR. Acute in vivo regulation of 11ß-hydroxysteroid dehydrogenase type 1 activity by insulin and intralipid infusions in humans. Journal of Clinical Endocrinology and Metabolism 200691 4682-4688. (doi:10.1210/jc.2006-0819)
44 Balachandran A, Guan H, Sellan M, van Uum S \& Yang K. Insulin and dexamethasone dynamically regulate adipocyte $11 \beta$-hydroxysteroid dehydrogenase type 1. Endocrinology 2008149 4069-4079. (doi:10.1210/en.2008-0088)

45 Jamieson PM, Chapman KE, Edwards CR \& Seckl JR. 11ß-hydroxysteroid dehydrogenase is an exclusive $11 \beta$-reductase in primary cultures of rat hepatocytes: effect of physicochemical and hormonal manipulations. Endocrinology 1995136 4754-4761.

46 Lindsay RS, Wake DJ, Nair S, Bunt J, Livingstone DE, Permana PA, Tataranni PA \& Walker BR. Subcutaneous adipose $11 \beta$-hydroxysteroid dehydrogenase type 1 activity and messenger ribonucleic acid levels are associated with adiposity and insulinemia in Pima Indians and Caucasians. Journal of Clinical Endocrinology and Metabolism $2003 \mathbf{8 8}$ 2738-2744. (doi:10.1210/jc.2002-030017)

47 Zhu L, Hou M, Sun B, Burén J, Zhang L, Yi J, Hernell O \& Li X. Testosterone stimulates adipose tissue $11 \beta$-hydroxysteroid dehydrogenase type 1 expression in a depot-specific manner in children. Journal of Clinical Endocrinology and Metabolism 201095 3300-3308. (doi:10.1210/jc.2009-2708)

Received 16 December 2013

Revised version received 27 March 2014

Accepted 15 April 2014 